\title{
Noonan syndrome - a new survey
}

Alireza Tafazoli ${ }^{1}$, Peyman Eshraghi ${ }^{2}$, Zahra Kamel Koleti ${ }^{3}$, Mohammadreza Abbaszadegan $^{4}$

\author{
${ }^{1}$ Medical Genetics Research Center, Medical School, Mashhad University of Medical \\ Sciences, Mashhad, Iran \\ ${ }^{2}$ Department of Pediatrics, Imam Reza Hospital, Mashhad University of Medical \\ Sciences, Mashhad, Iran \\ ${ }^{3}$ Department of Pathology and Medical laboratory, Shohada Hospital, Mazandaran \\ University of Medical Sciences, Sari, Iran \\ ${ }^{4}$ Division of Human Genetics, Immunology Research Center, Avicenna Research \\ Institute, Mashhad University of Medical Sciences, Mashhad, Iran
}

Submitted: 5 January 2015

Accepted: 16 February 2015

Arch Med Sci 2017; 13, 1: 215-222

DOI: 10.5114 /aoms.2017.64720

Copyright (C2016 Termedia \& Banach

\begin{abstract}
Noonan syndrome (NS) is an autosomal dominant disorder with vast heterogeneity in clinical and genetic features. Various symptoms have been reported for this abnormality such as short stature, unusual facial characteristics, congenital heart abnormalities, developmental complications, and an elevated tumor incidence rate. Noonan syndrome shares clinical features with other rare conditions, including LEOPARD syndrome, cardio-facio-cutaneous syndrome, Noonan-like syndrome with loose anagen hair, and Costello syndrome. Germline mutations in the RAS-MAPK (mitogen-activated protein kinase) signal transduction pathway are responsible for NS and other related disorders. Noonan syndrome diagnosis is primarily based on clinical features, but molecular testing should be performed to confirm it in patients. Due to the high number of genes associated with NS and other RASopathy disorders, next-generation sequencing is the best choice for diagnostic testing. Patients with NS also have higher risk for leukemia and specific solid tumors. Age-specific guidelines for the management of NS are available.
\end{abstract}

Key words: Noonan syndrome, RAS-MAPK signaling pathways, germline mutation.

\section{Introduction}

Noonan syndrome (NS, OMIM 163950) is known as a multisystem disease with a wide spectrum of heterogeneity regarding the genetic and clinical characteristics. Despite the autosomal dominant traits of the majority of NS cases, autosomal recessive transmission has also been reported in a few cases. Sporadic and familial types of transmission have been reported in NS cases, but most cases follow a sporadic pattern which is suggested to be the consequence of new mutations [1-5]. Noonan syndrome is characterized by reduced postnatal growth, distinctive facial dysmorphism, a wide spectrum of congenital heart defects (CHDs), learning difficulties, short stature, renal anomalies, lymphatic malformations, bleeding disorders, and skeletal malformations [2, 6, 7]. Due to the extensive diversity of phenotypic properties in NS, clinical overlaps have been detected between Noonan and other autosomal dominant disorders such as LEOPARD syndrome, cardio-facio-cutaneous syndrome,

\author{
Corresponding author: \\ Prof. Mohammadreza \\ Abbaszadegan \\ Division \\ of Human Genetics \\ Immunology Research Center \\ Avicenna Research Institute \\ Mashhad University \\ of Medical Sciences \\ Vakil abad Blv. \\ 9177948988 Mashhad, Iran \\ Phone: +98 9151156121 \\ E-mail: Abbaszadeganmr@ \\ mums.ac.ir
}


NS-like syndrome with loose anagen hair, and Costello syndrome [8]. The prevalence and global frequency of NS at live birth almost all over the world has been reported as one in 1000-2500 individuals, which makes it the second cause of congenital heart disease next to trisomy $21[2,9,10]$.

Noonan syndrome was first introduced by Jacqueline Noonan following her investigations on 9 patients with pulmonic stenosis (PS), chest deformities and unique facial dysmorphic features such as hypertelorism, ptosis, low-set ears, and webbed neck [11]. Figure 1 shows NS patients with these symptoms and clinical manifestations. Germline mutations in the RAS-MAPK (mitogenactivated protein kinase) pathway are responsible for NS and other related disorders. Genes in this pathway include PTPN11, SOS1, RAF1, BRAF, HRAS, KRAS, NRAS, SHOC, MAP2K1, MAP2K2, and CBL. Recently, mutations in RIT1, RASA2, and $A 2 M L 1$ have also been shown to cause NS. Therefore, NS is referred to as a heterogeneous condition [3, 8, 12]. Because PTPN11 and other genes such as KRAS, HRAS, NRAS, and BRAF have essential roles in the RAS-MAPK pathway, patients with NS are predisposed to leukemia and certain solid tumors [13].

\section{Clinical features and symptoms}

Noonan syndrome has several medical and developmental features that can be detected both pre- and postnatally. According to previous studies, there are various unusual prenatal presentations which should be regarded as risk factors of NS. In some cases the karyotype of the fetus might be normal but symptoms such as polyhydramnios, hydronephrosis, pleural effusion, edema, cardiac abnormalities, distended jugular, lymphatic sacs, cystic hygroma, and elevated nuchal are other possible signs of the NS. These prenatal features can be identified during the first or second trimester [14-18]. After birth, Noonan patients show a wide range of observable and internal symptoms through the lifetime including hearing and digestive problems, abnormal height and skin pigmentation, unilateral or bilateral cryptorchidism in up to $80 \%$ of boys, hematological disorders, lymphatic abnormalities, multiple giant cell lesions, spinal and chest deformities, joint, tendon, and bursa lesions, widely spaced nipples, webbed neck, cubitus valgus, genu valgum, mild intellectual impairment, social cognition difficulties, language impairments including reading and spelling difficulties, and eyes abnormalities including ptosis and hypertelorism, excess nuchal skin, and swollen edematous dorsa of hands and feet. Wispy hair, thickly hooded prominent eyes, wide-based depressed nose with bulbous, higharched palate, upturned lips, and a cupid-bow appearance of the upper lips are more frequently seen in infants than older children with NS [7]. Patients are also predisposed to cancers such as juvenile myelomonocytic leukemia and neuroblastoma [19-26]. The main facial presentations of NS are proposed to be head size relative to face, tall forehead, hypertelorism, down-slanting palpebral fissures, epicanthal folds, short wide nose with depressed nasal root and full tip, severely grooved philtrum, wide peaks of the vermilion border of the upper lip, small jaw and short neck, and lowset and posteriorly rotated ears with oval-shaped and thick helixes $[7,27]$. Heart defects are present in more than $80 \%$ of patients, and timely diagnosis of the NS will positively affect the treatment of choice, outcome, and prognosis [21, 28]. The most prevalent congenital heart defects are pulmonary valve stenosis, atrial septal defect, ostium secundum type, and stenosis of the peripheral pulmonary arteries which is related to PTPN11 gene mutation. Ventricular septal defect and most left-sided heart defects show a trend toward overrepresentation in patients with other mutations $[14,29]$. It has been observed that specific gene mutations lead to specific heart problems; for example, RAF1 mutations are usually related to hy-
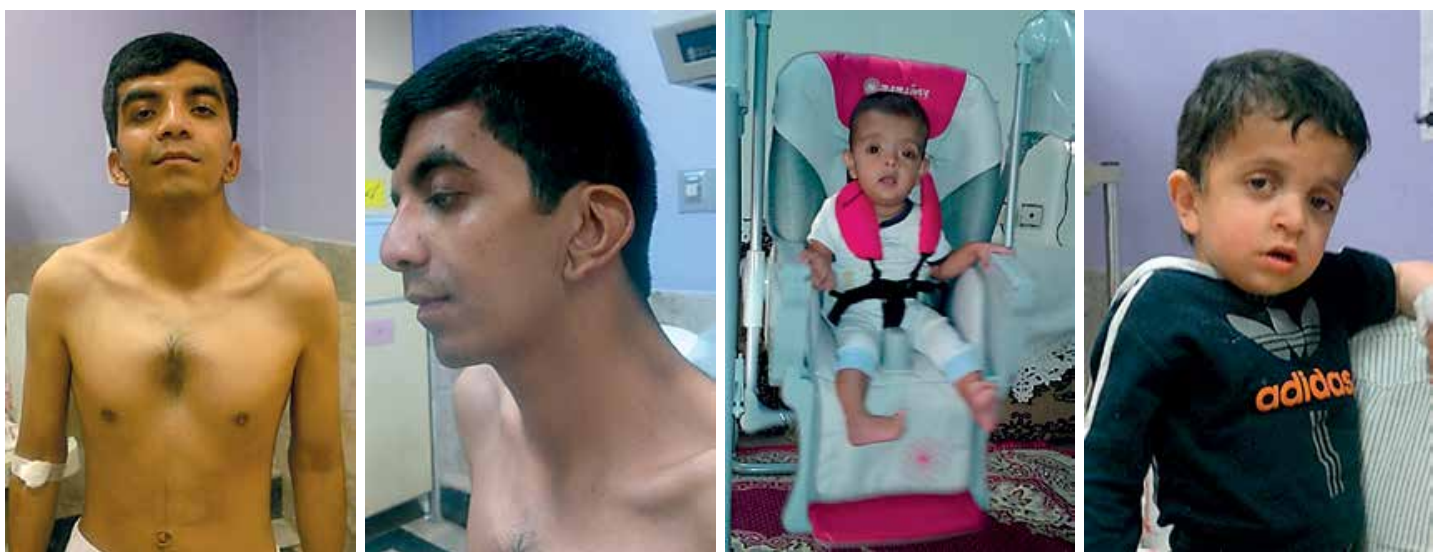

Figure 1. Noonan syndrome at different ages 
pertrophic cardiomyopathy rather than other cardiac problems [21]. Table I lists clinical symptoms of patients with NS.

\section{Genetics of Noonan syndrome}

Autosomal dominant abnormalities called RASopathies are the results of germline mutations in the intracellular RAS/mitogen-activated protein kinase (MAPK) pathway which can lead to NS and the associated abnormalities.

The RAS-MAPK pathway is known as the principal signal transduction cascade involved in cell cycle differentiation, growth, and senescence through adjusting morphology determination, organogenesis, and synaptic plasticity (Figure 2) [1, 8, 30]. Both downstream and upstream gene mutations in the RAS-MAPK pathway are related to specific complications which can cause a wide range of possible developmental abnormalities in NS [31]. Also recent studies indicated that mutations in three other genes - RIT1, RASA2 and A2ML1 - result in NS and related disorders. Investigations on new mutations in $A 2 M L 1$, a gene responsible for protease inhibitor $\alpha 2$-macroglobulin (A2M)-like-1 expression, led to the development of a syndrome clinically related to Noonan disorder [12]. The other RASopathy disorders show mutations in specific genes. LEOPARD syndrome (LS, OMIM 151100) is associated with PTPN11, RAF1 and BRAF gene mutations, Noonan-like syndrome with loose anagen hair (NS/LAH, OMIM 607721) with SHOC2 gene mutations, cardio-facial-cutaneous syndrome (CFCS, OMIM 115150) with KRAS, BRAF, MEK 1 and MEK2 gene mutations and Costello syndrome (CS, OMIM 218040) with HRAS gene mutations [32-46].

Mutations in PTPN11, which is involved in protein tyrosine phosphatase SHP-2 expression, on chromosome 12 (12q24), account for up to 50\% of NS patients. PTPN11 is expressed in various tissues and is involved in adjusting the eukaryotic cells' reflexes to multiple extracellular stimuli, such as hormones, cytokines, and growth factors. Activation of SHP-2 results from binding of the $\mathrm{N}$-terminal-SH2 (N-SH2) domains to short amino acid motifs containing a phosphotyrosyl residue. Most of the mutations are the missense type and occur in exons 3, 8, and 13, which contain the $\mathrm{N}-\mathrm{SH} 2$ domain and PTP domains. Gain-of-function is the effect of the mutations, resulting in over-activation of RAS-MAPK pathway molecules [32, 47-49]. Other associated genes include SOS1 (approximately 10\%), RAF1 (approximately 10\%), MEK 1 (less than 4\%), KRAS (less than 2\%) and NRAS (less than 1\%) [2, 50]. However, there are no distinct statistical data for the role of novel genes related to NS. In one study the investigators found that RIT1 is involved in $9 \%$ of Noonan cases, but this number may be different in other populations
Table I. Clinical features in Noonan syndrome (from $[1,5,18,27])$

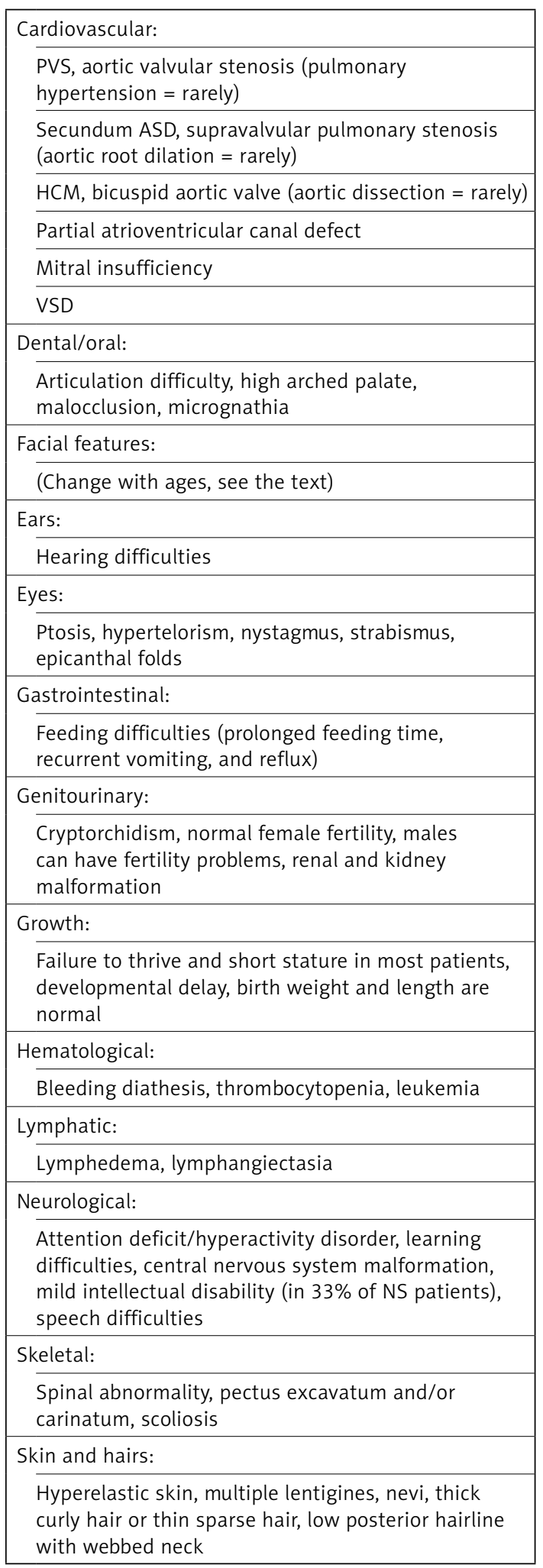

[33]. Based on the different gene mutations, NS can be divided into categories with associated clinical features; for instance, In NS type 1 (OMIM 163950), PTPN11 mutations can lead to extended 


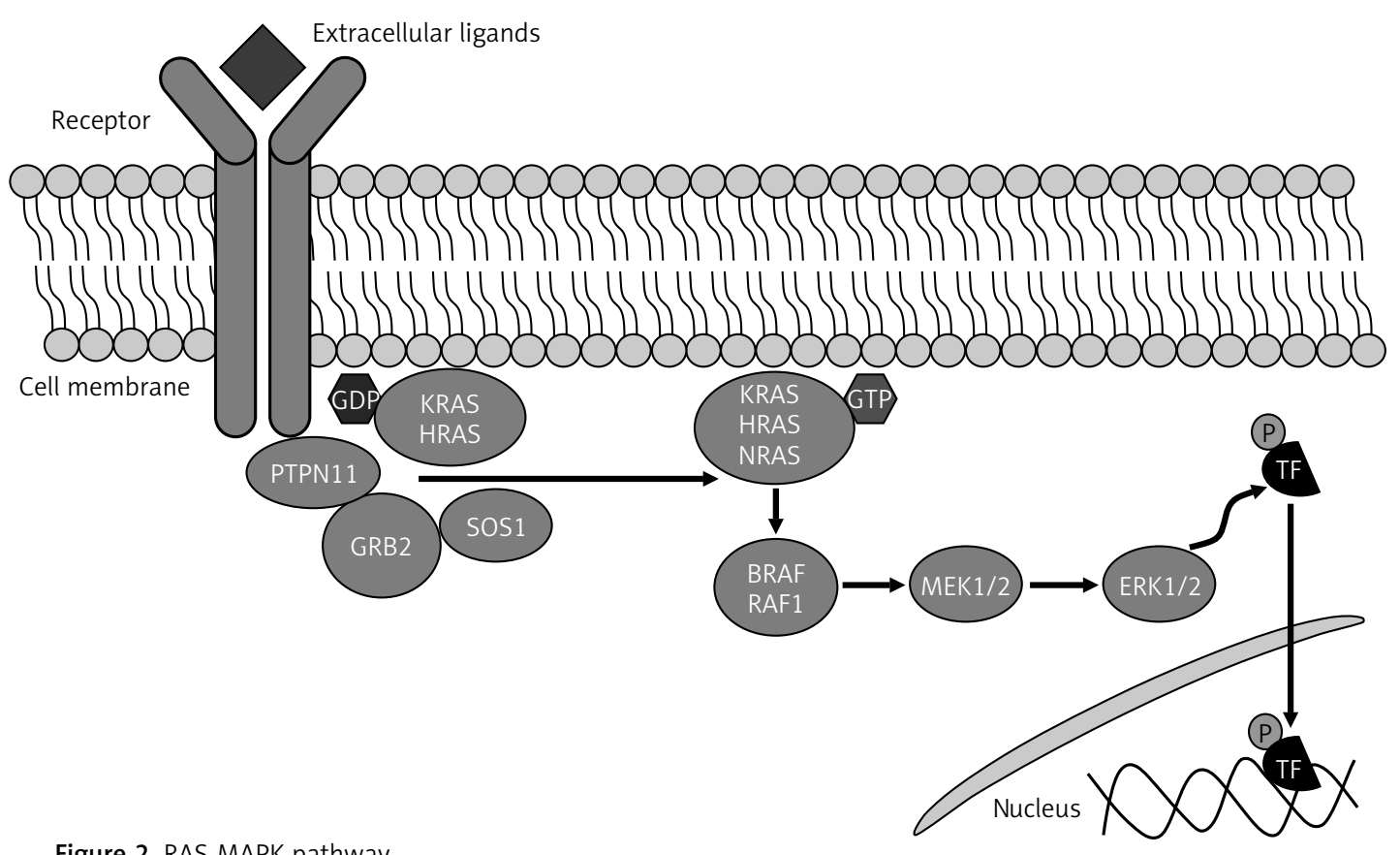

pulmonary stenosis, lower hypertrophic cardiomyopathy, and atrial septal abnormality (ostium secundum type), shorter stature, lower insulin growth factor-1 (IGF1) levels, more bleeding diathesis and juvenile myelomonocytic leukemia. On the other hand, in NS type 3 (OMIM 609942), KRAS mutations have been detected due to more hypertrophic cardiomyopathy and naevi, lentigines, and café au lait spots. In this regard based on the location of the mutations responsible for NS occurrence, different types of NS presentations might be detected in patients. These divisions can be useful to determine genotype-phenotype correlations $[2,5,32,36,51]$.

\section{Diagnosis (clinical and molecular)}

Conducting obstetric ultrasound and fetal echocardiography during the prenatal screening as the main diagnosis methods is strongly recommended for patients with possible clinical signs of NS in their fetus or those with first-degree family with NS. Based on the literature obstetric ultrasound is suggested to be performed at 12-14 and 20 weeks of gestation and again in the third trimester and fetal echocardiography at 18-20 weeks of gestation. DNA from blood, chorionic villi, or amniotic fluid can be analyzed for mutations [18]. Facial and musculoskeletal abnormalities mostly result in the primary diagnosis of NS. Although the facial features associated with NS change with age [14, 52], the clinical manifestations are sufficient to be the first step to diagnosis.

With many similarities in clinical manifestations displayed between NS and other RASopathies, differential diagnosis is still based on dif- ferences in clinical features and symptoms. Also, other disorders such as Aarskog syndrome/faciogenital dysplasia, Baraitser-Winter syndrome, fetal alcohol syndrome, neurofibromatosis type 1 , and Turner syndrome share many features with NS. These cases can be diagnosed by molecular testing in addition to different clinical symptoms and signs [5]. Van der Burgt diagnostic criteria (Table II) are commonly used to distinguish patients with NS [53]. All cases should be confirmed by molecular testing for appropriate specific treatments and follow-up procedures in addition to making correct genotype-phenotype correlations. Despite various recognized gene mutations involved in NS in $15-30 \%$ of cases the responsible genes are not clear [3, 8]. Karyotype and copy number analysis are suggested only in cases with intense neurocognitive involvement and are not performed routinely for patients with typical phenotypes of NS. However, subtle chromosomal abnormalities may be detected using array comparative genomic hybridization (aCGH) [5, 50, 51, 54-56].

DNA sequencing is the gold standard for the detection of genetic variants; however, due to the high number of genes associated with NS and other RASopathy disorders, standard diagnostic testing using Sanger sequencing is expensive and time-consuming [8]. Currently, next-generation sequencing (NGS) is faster and more accurate and cost-effective for the diagnosis of RASopathies than Sanger sequencing $[3,8]$. Next-generation sequencing is a useful approach for finding genetic variants in locus heterogeneity conditions such retinitis pigmentosa, hypertrophic cardiomyopathy, and NS [57]. Next-generation sequencing 
Table II. Diagnostic criteria for Noonan syndrome

\begin{tabular}{|c|c|c|}
\hline Feature & $A=$ Major & $B=$ Minor \\
\hline Facial & $\begin{array}{l}\text { Typical facial dysmorphology } \\
\text { (also change with age) }\end{array}$ & Suggestive facial dysmorphology \\
\hline Cardiac & $\begin{array}{l}\text { Pulmonary valve stenosis, } \\
\text { HOCM and/or ECG } \\
\text { Typical of Noonan syndrome }\end{array}$ & Other defect \\
\hline Height & $<P 3^{*}$ & $<\mathrm{P} 10^{*}$ \\
\hline Chest wall & Pectus carinatum/excavatum & Broad thorax \\
\hline Family history & $\begin{array}{l}\text { First-degree relative with definite Noonan } \\
\text { syndrome }\end{array}$ & $\begin{array}{l}\text { First-degree relative with suggestive } \\
\text { Noonan syndrome }\end{array}$ \\
\hline Other features & $\begin{array}{l}\text { Mental retardation, cryptorchidism, } \\
\text { and lymphatic vessel dysplasia }\end{array}$ & $\begin{array}{c}\text { One of mental retardation, cryptorchidism, } \\
\text { or lymphatic vessel dysplasia }\end{array}$ \\
\hline
\end{tabular}

RASopathy panels for specific genes and targeted resequencing (Centogene, Germany) result in more efficient and rapid mutation detection than previous methods. Subsequent protein modeling to analyze the mutations and characterize the effects of protein structure changes on patient phenotypic signs and symptoms in many areas of research is becoming routine $[58,59]$.

\section{Genetic counseling}

Noonan syndrome in patients with PTPN11 mutations is more likely to be familial than NS without PTPN11 mutations $[6,60]$. Because facial phenotype tend to normalization as the patient grows up, it is helpful for diagnosis to review childhood photographs of both parents [18]. There is almost $50 \%$ likelihood for a mutation to be inherited by a child who has parents with NS. The risk of occurrence of NS in the first degree relatives of an affected person is $50 \%$, but if the parents are unaffected the risk is less than $1 \%$ in siblings. Because of the wide variety of NS representations, the responsible patient of a child with NS might be undiagnosed. In most cases heterogeneous NS might be the consequence of sporadic mutations with symptoms similar to other syndromes. Pre-implantation genetic diagnosis (PGD) is a diagnostic technique used for screening embryos of cases with known mutations [4, 27, 61].

\section{Management}

Due to the wide spectrum of symptoms and presentations in Noonan cases, accurate clinical and genetically diagnosis and comprehensive management of the disorder is strongly recommended. Despite the ordinary intellectual and physical capacities in Noonan cases, multidisciplinary assessments and follow-up screenings are suggested for patients $[5,18]$.
Age-specific guidelines for management that emphasize screening and testing for common health issues are available [27].

The NS Support Group (NSSG) is a supportive organization involved in designing guidelines regarding the diagnosis and management of NS through recent genetic findings [5] http://healthfinder.gov/FindServices/Organizations/Organization.aspx?code=HR2560. Moreover there are some other websites which have a parents' guide that provides useful information and guidelines for people affected by NS. Table III lists the management guidelines for patients with Noonan syndrome.

\section{Cancer risk in patients with Noonan syndrome}

Because PTPN11 and other genes such as KRAS, HRAS, NRAS, and BRAF have essential roles in the RAS-MAPK signal transduction pathway, which controls several developmental processes, it is not surprising that patients with NS are predisposed to benign or malignant cell proliferative disease [13]. According to previous estimates, the occurrence rate of hematological malignancies was highest among patient with NS when compared with other cancers [13]. Mild myeloproliferative disorder occurs in almost $10 \%$ of children with NS, and a lower portion of cases reveals juvenile myelomonocytic leukemia (JMML) [62-64] and/or other hematological malignancies [65-71].

Some missense mutations in PTPN11 are detected in patients with myeloid and lymphoid malignancies which are also identified as principal mutations in NS cases [72]. The prevalence of solid tumors including neuroblastoma and embryonal rhabdomyosarcoma has been reported to be elevated in some cases with NS patients [73-80]. Low rates of somatic mutations in PTPN11 have also been identified in solid tumors of the lung and liver, and colorectal malignancies [80, 81]. 
Table III. Management guidelines for patients with Noonan syndrome (from $[2,27]$ )

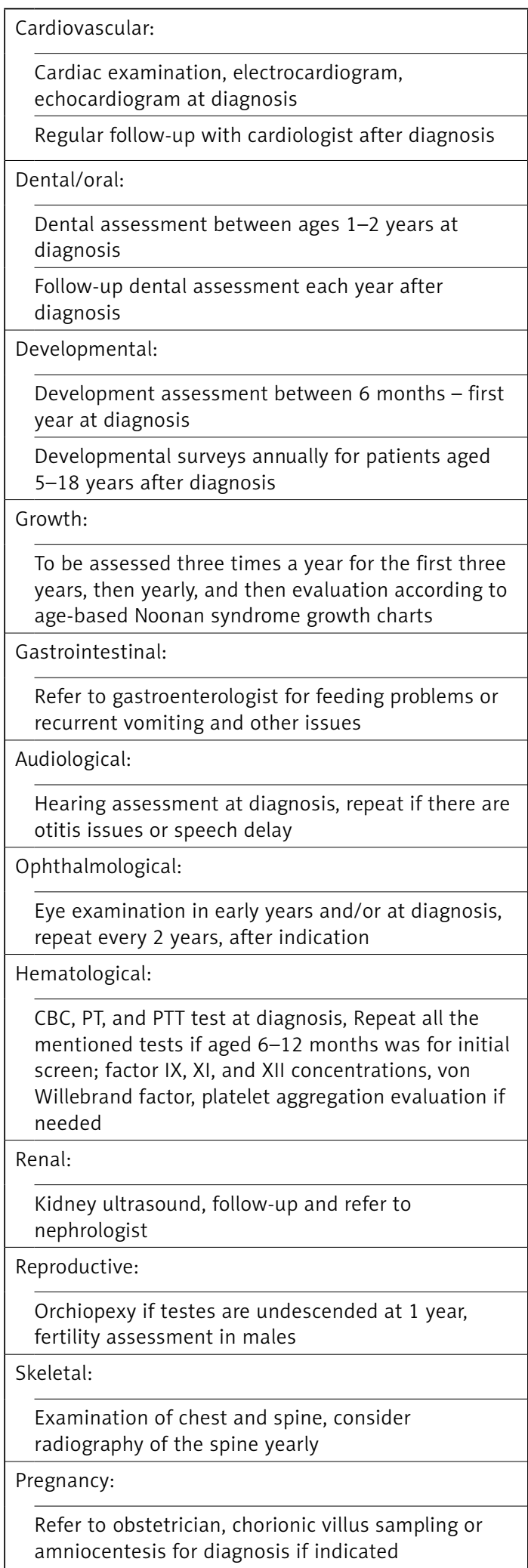

Most findings support a PTPN11 mutation in Noonan patients with malignancies, but mutations in other genes in RAS-MAPK pathways have also been associated with cancers in NS and other related disorders. For instance, mutation in HRAS was also seen in Costello syndrome, with an increasing incidence of tumors [82].

\section{Conclusions}

Because of the heterogeneity in both clinical and genetic characteristics of NS, every physician should be aware of the complexity of this disorder. Many interesting aspects of NS are remained unsolved; these include the near absence of large families with NS, all cohorts in studies of NS having included more male than female patients [18], and the fact that the genes and/or mutations responsible for $15-30 \%$ of cases have not yet been identified [3]. Continuous follow-up of patients is essential to control the medical and developmental implications of NS. Many questions regarding the molecular and genetic causes of NS have yet to be answered [2].

\section{Acknowledgments}

The authors thank Prof. Marco Tartaglia for his valuable guidance and discussion.

\section{Conflict of interest}

The authors declare no conflict of interest.

\section{References}

1. Tartaglia M, Gelb BD, Zenker M. Noonan syndrome and clinically related disorders. Best Pract Res Clin Endocrinol Metabol 2011; 25: 161-79.

2. Roberts AE, Allanson JE, Tartaglia M, Gelb BD. Noonan syndrome. Lancet 2013; 381: 333-42.

3. Chen PC, Yin J, Yu HW, et al. Next-generation sequencing identifies rare variants associated with Noonan syndrome. Proc Natl Acad Sci USA 2014; 111: 11473-8.

4. van der Burgt I, Brunner H. Genetic heterogeneity in Noonan syndrome: evidence for an autosomal recessive form. Am J Med Genet 2000; 94: 46-51.

5. Romano AA, Allanson JE, Dahlgren J, et al. Noonan syndrome: clinical features, diagnosis, and management guidelines. Pediatrics 2010; 126: 746-59.

6. Tartaglia M, Kalidas K, Shaw A, et al. PTPN11 mutations in Noonan syndrome: molecular spectrum, genotype-phenotype correlation, and phenotypic heterogeneity. Am J Hum Genet 2002; 70: 1555-63.

7. Lepri F, De Luca A, Stella L, et al. SOS1 mutations in Noonan syndrome: molecular spectrum, structural insights on pathogenic effects, and genotype-phenotype correlations. Hum Mutat 2011; 32: 760-72.

8. Lepri FR, Scavelli R, Digilio MC, et al. Diagnosis of Noonan syndrome and related disorders using target next generation sequencing. BMC Med Genet 2014; 15: 14.

9. Binder G, Grathwol S, von Loeper K, et al. Health and quality of life in adults with Noonan syndrome. J Pediatr 2012; 161: 501-5. e1.

10. Mendez HM, Opitz JM, Reynolds JF. Noonan syndrome: a review. Am J Med Genet 1985; 21: 493-506.

11. Noonan JA. Hypertelorism with Turner phenotype: a new syndrome with associated congenital heart disease. Am J Dis Child 1968; 116: 373-80. 
12. Vissers LE, Bonetti M, Paardekooper Overman J, et al. Heterozygous germline mutations in A2ML1 are associated with a disorder clinically related to Noonan syndrome. Eur J Hum Genet 2015; 23: 317-24.

13. Jongmans MC, van der Burgt I, Hoogerbrugge PM, et al. Cancer risk in patients with Noonan syndrome carrying a PTPN11 mutation. Eur J Hum Genet 2011; 19: 870-4.

14. Sharland M, Burch M, McKenna W, Paton M. A clinical study of Noonan syndrome. Arch Dis Child 1992; 67: 178-83.

15. Nisbct DL, Griffin R, Chitty LS. Prenatal features of Noonan syndrome. Prenat Diagn 1999; 19: 642-7.

16. Reynders CS, Pauker SP, Benacerraf BR. First trimester isolated fetal nuchal lucency: significance and outcome. J Ultrasound Med 1997; 16: 101-5.

17. Maheshwari M, Belmont J, Fernbach S, et al. PTPN11 mutations in Noonan syndrome type I: detection of recurrent mutations in exons 3 and 13. Hum Mutat 2002 20: 298-304.

18. Van der Burgt I. Noonan syndrome. Orphanet J Rare Dis 2007; 2: 282-3.

19. Hakim FA, Gruden JF, Panse PM, Alegria JR. Coronary artery ectasia in an adult Noonan syndrome detected on coronary CT angiography. Heart Lung Circ 2013; 22 1051-3.

20. Qiu WW, Yin SS, Stucker FJ. Audiologic manifestations of Noonan syndrome. Otolaryngol Head Neck Surg 1998; 118: 319-23.

21. Prendiville TW, Gauvreau K, Tworog-Dube E, et al. Cardiovascular disease in Noonan syndrome. Arch Dis Child 2014; 99: 629-34.

22. Cremers C, Van der Burgt C. Hearing loss in Noonan syndrome. Int J Pediatr Otorhinolaryngol 1992; 23: 81-4.

23. Bufalino A, Carrera M, Carlos R, Coletta RD. Giant cell lesions in Noonan syndrome: case report and review of the literature. Head Neck Pathol 2010; 4: 174-7.

24. Naficy S, Shepard NT, Telian SA. Multiple temporal bone anomalies associated with Noonan syndrome. Otolaryngol Head Neck Surg 1997; 116: 265-7.

25. Marino B, Digilio MC, Toscano A, Giannotti A, Dallapicco la B. Congenital heart diseases in children with Noonan syndrome: an expanded cardiac spectrum with high prevalence of atrioventricular canal. J Pediatr 1999; 135: 703-6

26. Cobben JM, Oostra RJ, van Dijk FS. Pectus excavatum and carinatum. Eur J Med Genet 2014; 57: 414-7.

27. Bhambhani V, Muenke M. Noonan syndrome. Am Fam Phys 2014; 89: 37-43.

28. Lin AE, Basson CT, Goldmuntz E, et al. Adults with genetic syndromes and cardiovascular abnormalities: clinical history and management. Genet Med 2008; 10: 469-94.

29. Sznajer Y, Keren B, Baumann C, et al. The spectrum of cardiac anomalies in Noonan syndrome as a result of mutations in the PTPN11 gene. Pediatrics 2007; 119: e1325-e31.

30. Tidyman WE, Rauen KA. The RASopathies: developmental syndromes of Ras/MAPK pathway dysregulation. Curr Opin Genet Develop 2009; 19: 230-6.

31. Pierpont El, Pierpont ME, Mendelsohn NJ, et al. Effects of germline mutations in the Ras/MAPK signaling pathway on adaptive behavior: cardiofaciocutaneous syndrome and Noonan syndrome. Am J Med Genet Part A 2010; 152: 591-600.

32. Tartaglia M, Mehler EL, Goldberg R, et al. Mutations in PTPN11, encoding the protein tyrosine phosphatase SHP-2, cause Noonan syndrome. Nat Genet 2001; 29 : $465-8$
33. Aoki Y, Niihori T, Banjo T, et al. Gain-of-function mutations in RIT1 cause Noonan syndrome, a RAS/MAPK pathway syndrome. Am J Hum Genet 2013; 93: 173-80.

34. Tartaglia M, Pennacchio LA, Zhao C, et al. Gain-of-function SOS1 mutations cause a distinctive form of Noonan syndrome. Nat Genet 2006; 39: 75-9.

35. Carta C, Pantaleoni F, Bocchinfuso G, et al. Germline missense mutations affecting KRAS Isoform $B$ are associated with a severe Noonan syndrome phenotype. Am J Hum Genet 2006; 79: 129-35.

36. Schubbert S, Zenker M, Rowe SL, et al. Germline KRAS mutations cause Noonan syndrome. Nature Genet 2006; 38: 331-6.

37. Pandit B, Sarkozy A, Pennacchio LA, et al. Gain-of-function RAF1 mutations cause Noonan and LEOPARD syndromes with hypertrophic cardiomyopathy. Nat Genet 2007; 39: 1007-12.

38. Aoki Y, Niihori T, Kawame H, et al. Germline mutations in HRAS proto-oncogene cause Costello syndrome. Nat Genet 2005; 37: 1038-40.

39. Cirstea IC, Kutsche K, Dvorsky R, et al. A restricted spectrum of NRAS mutations causes Noonan syndrome. Nat Genet 2010; 42: 27-9.

40. Denayer E, Peeters H, Sevenants L, Derbent M, Fryns JP, Legius E. NRAS mutations in Noonan syndrome. Mol Syndromol 2012; 3: 34-8.

41. Gos M, Fahiminiya S, Poznański J, et al. Contribution of RIT1 mutations to the pathogenesis of Noonan syndrome: four new cases and further evidence of heterogeneity. Am J Med Genet A 2014; 164A: 2310-6.

42. Martinelli S, De Luca A, Stellacci E, et al. Heterozygous germline mutations in the CBL tumor-suppressor gene cause a Noonan syndrome-like phenotype. Am J Hum Genet 2010; 87: 250-7.

43. Nava C, Hanna N, Michot C, et al. Cardio-facio-cutaneous and Noonan syndromes due to mutations in the RAS/MAPK signalling pathway: genotype-phenotype relationships and overlap with Costello syndrome. J Med Genet 2007; 44: 763-71.

44. Niihori T, Aoki Y, Narumi Y, et al. Germline KRAS and BRAF mutations in cardio-facio-cutaneous syndrome. Nat Genet 2006; 38: 294-6.

45. Razzaque MA, Nishizawa T, Komoike Y, et al. Germline gain-of-function mutations in RAF1 cause Noonan syndrome. Nat Genet 2007; 39: 1013-7.

46. Sarkozy A, Carta C, Moretti S, et al. Germline BRAF mutations in Noonan, LEOPARD, and cardiofaciocutaneous syndromes: molecular diversity and associated phenotypic spectrum. Hum Mutat 2009; 30: 695-702.

47. Hung CS, Lin JL, Lee YJ, Lin SP, Chao MC, Lo FS. Mutational analysis of PTPN11 gene in Taiwanese children with Noonan syndrome. J Form Med Assoc 2007; 106: 169-72.

48. Essawi ML, Ismail MF, Afifi HH, Kobesiy MM, El Kotoury A, Barakat MM. Mutational analysis of the PTPN11 gene in Egyptian patients with Noonan syndrome. J Form Med Assoc 2013; 112: 707-12.

49. Pluskey S, Wandless TJ, Walsh CT, Shoelson SE. Potent stimulation of SH-PTP2 phosphatase activity by simultaneous occupancy of both SH2 domains. J Biol Chem 1995; 270: 2897-900.

50. Jorge AA, Malaquias AC, Arnhold IJ, Mendonca BB. Noonan syndrome and related disorders: a review of clinical features and mutations in genes of the RAS/ MAPK pathway. Horm Res Paediatr 2009; 71: 185-93.

51. Shchelochkov OA, Patel A, Weissenberger GM, et al. Duplication of chromosome band $12 q 24.11 q 24.23$ results 
in apparent Noonan syndrome. Am J Med Genet A 2008; 146: $1042-8$

52. Allanson J, Hall J, Hughes $\mathrm{H}$, et al. Noonan syndrome: the changing phenotype. Am J Med Genet 1985; 21: 507-14.

53. Van Der Burgt I, Berends E, Lommen E, Van Beersum S, Hamel B, Mariman E. Clinical and molecular studies in a large Dutch family with Noonan syndrome. Am J Med Genet 1994; 53: 187-91.

54. Cabalun MR, Miro R, Egozcue J. Abnormal phenotype in a child with the same balanced translocation $(5 ; 7)(\mathrm{p} 15$; q22) as his father. Clin Genet 1981; 20: 428-31.

55. Chery M, Philippe C, Worms A, Gilgenkrantz S. The Noonan syndrome. The Nancy experience revisited. Genet Counsel (Geneva, Switzerland) 1992; 4: 113-8.

56. Onufer C, Stephan M, Thuline H, Char F. Chromosome 13 long arm interstitial deletion associated with features of Noonan phenotype. Ann Genet 1987, 30: 236-9.

57. Tobias ES, Connor M, Ferguson-Smith M. Essential Medical Genetics. $6^{\text {th }}$ ed. Wiley-Blackwell 2011.

58. Abbaszadegan MR, Hassani S, Vakili R, et al. Two nove mutations in CYP11B1 and modeling the consequent alterations of the translated protein in classic congenital adrenal hyperplasia patients. Endocrine 2013; 44: 212-9.

59. Moghaddasian M, Arab H, Dadkhah E, Boostani H, Babak AR, Abbaszadegan MR. Protein modeling of cathepsin C mutations found in Papillon-Lefèvre syndrome. Gene 2014; 538: 182-7.

60. Yoshida R, Hasegawa T, Hasegawa Y, et al. Protein-tyrosine phosphatase, nonreceptor type 11 mutation analysis and clinical assessment in 45 patients with Noonan syndrome. J Clin Endocrinol Metabol 2004; 89: 3359-64.

61. Razzaque M, Komoike Y, Nishizawa T, et al. Characterization of a novel KRAS mutation identified in Noonan syndrome. Am J Med Genet A 2012; 158: 524-32.

62. Choong K, Freedman MH, Chitayat D, Kelly EN, Taylor G, Zipursky A. Juvenile myelomonocytic leukemia and Noonan syndrome. J Pediatr Hematol Oncol 1999; 21: 523-7.

63. Lauchle JO, Braun BS, Loh ML, Shannon K. Inherited predispositions and hyperactive Ras in myeloid leukemogenesis. Pediatr Blood Cancer 2006; 46: 579-85.

64. Tartaglia M, Niemeyer CM, Shannon KM, Loh ML SHP-2 and myeloid malignancies. Curr Opin Hematol 2004; 11: 44-50.

65. Chantrain CF, Jijon P, De Raedt T, et al. Therapy-related acute myeloid leukemia in a child with Noonan syndrome and clonal duplication of the germline PTPN11 mutation. Pediatr Blood Cancer 2007; 48: 101-4.

66. Ferrero GB, Baldassarre G, Delmonaco AG, et al. Clinical and molecular characterization of 40 patients with Noonan syndrome. Eur J Med Genet 2008; 51: 566-72.

67. Karow A, Steinemann D, Göhring G, et al. Clonal duplication of a germline PTPN11 mutation due to acquired uniparental disomy in acute lymphoblastic leukemia blasts from a patient with Noonan syndrome. Leukemia 2007; 21: 1303-5.

68. La Starza R, Rosati R, Roti G, et al. A new NDE1/PDGFRB fusion transcript underlying chronic myelomonocytic leukaemia in Noonan syndrome. Leukemia 2007; 21 830-3.

69. Lo FS, Kuo TT, Wang CJ, Kuo MT, Kuo MC. Hodgkin's lymphoma in a patient with Noonan syndrome with germline PTPN11 mutations. Int J Hematol 2008; 88: 287-90.

70. Matsubara K, Yabe H, Ogata T, Yoshida R, Fukaya T. Acute myeloid leukemia in an adult Noonan syndrome patient with PTPN11 mutation. Am J Hematol 2005; 79: 171-2.
71. Roti G, La Starza R, Ballanti S, et al. Acute lymphoblastic leukaemia in Noonan syndrome. Br J Haematol 2006; 133: 448-50.

72. Tartaglia M, Gelb BD. Germ-line and somatic PTPN11 mutations in human disease. Eur J Med Genet 2005; 48 : 81-96.

73. Cotton J, Williams RG. Noonan syndrome and neuroblastoma. Arch Pediatr Adolesc Med 1995; 149: 1280-1.

74. Ijiri R, Tanaka Y, Kato K, Masuno M, Imaizumi K. A case of Noonan's syndrome with possible associated neuroblastoma. Pediatr Radiol 2000; 30: 432-3.

75. Jung A, Bechthold S, Pfluger T, Renner C, Ehrt O. Orbital rhabdomyosarcoma in Noonan syndrome. J Pediatr Hematol Oncol 2003; 25: 330-2.

76. Khan S, McDowell H, Upadhyaya M, Fryer A. Vaginal rhabdomyosarcoma in a patient with Noonan syndrome. J Med Genet 1995; 32: 743-5.

77. Kondoh T, Ishii E, Aoki Y, et al. Noonan syndrome with leukaemoid reaction and overproduction of catecholamines: a case report. Eur J Pediatr 2003; 162: 548-9.

78. Moschovi M, Touliatou V, Papadopoulou A, Mayakou MA, Nikolaidou-Karpathiou P, Kitsiou-Tzeli S. Rhabdomyosarcoma in a patient with Noonan syndrome phenotype and review of the literature. J Pediatr Hematol Oncol 2007; 29: 341-4.

79. Mutesa L, Pierquin G, Janin N, et al. Germline PTPN11 missense mutation in a case of Noonan syndrome associated with mediastinal and retroperitoneal neuroblastic tumors. Cancer Genet Cytogenet 2008; 182: 40-2.

80. Bentires-Alj M, Paez JG, David FS, et al. Activating mu tations of the noonan syndrome-associated SHP2/ PTPN11 gene in human solid tumors and adult acute myelogenous leukemia. Cancer Res 2004; 64: 8816-20.

81. Miyamoto D, Miyamoto M, Takahashi A, et al. Isolation of a distinct class of gain-of-function SHP-2 mutants with oncogenic RAS-like transforming activity from solid tumors. Oncogene 2008; 27: 3508-15.

82. Noonan JA. Noonan syndrome and related disorders: alterations in growth and puberty. Rev Endocr Metabol Disord 2006; 7: 251-5. 